\title{
SBDPs and Tau proteins for diagnosis and hypothermia therapy in neonatal hypoxic ischemic encephalopathy
}

\author{
HONGWEI WU, ZHENGUANG LI, XIA YANG, JINFENG LIU, WEI WANG and GANG LIU \\ Department of Neonatology, Xuzhou Children's Hospital, Xuzhou, Jiangsu 221002, P.R. China
}

Received July 19, 2016; Accepted November 3, 2016

DOI: 10.3892/etm.2016.3911

\begin{abstract}
The use of spectrin breakdown products (SBDPs) and Tau protein levels for diagnosis and a mild hypothermia therapy for treatment of neonatal hypoxic-ischemic encephalopathy (HIE) was evaluated. One hundred and fifty infants, with HIE within $12 \mathrm{~h}$ after birth, participated in the study. There were 30 newborns with mild symptoms, 60 with moderate symptoms, 60 with severe symptoms, and 30 in a control group. Regular therapy was used for the control and the mild HIE groups, and also for 30 cases in the group with moderate symptoms and for 30 in the group with severe symptoms. For the remaining infants, with moderate and severe symptoms, mild hypothermia therapy was used instead. A sandwich ELISA measured plasma concentrations of SBDPs and Tau proteins, at different time-points. For clinical follow-up, the neonatal behavioral neurological assessment (NBNA) assay and the Gesell development scale were performed at different time-points. The levels of SBDP and Tau proteins increased with the exacerbation of HIE, and decreased with the prolongation of therapy with statistically significant differences amongst groups. After treatment, the levels of SBDP and Tau proteins in groups with moderate and severe symptoms treated with mild hypothermia therapy were significantly lower than those of the groups treated with regular therapy. NBNA scores and the developmental quotient (DQ) were both worse with the increase in severity of HIE, however, the scores of groups with moderate and severe symptoms treated with mild hypothermia therapy were significantly better than those of groups treated with regular therapy $(\mathrm{P}<0.05)$. A gradual improvement of DQ was seen in the process of therapy in each group $(\mathrm{P}<0.05)$. According to a receiver operating character-
\end{abstract}

Correspondence to: Dr Zhenguang Li, Department of Neonatology, Xuzhou Children's Hospital, 18 Sudibei Road, Xuzhou, Jiangsu 221002, P.R. China

E-mail: zhenguangli29@163.com

Key words: spectrin breakdown products, Tau protein, hypoxic-ischemic encephalopathy, neonatal behavioral neurological assessment score, Gesell development scale, receiver operating characteristic curve istic (ROC) curve analysis, at a critical plasma concentration of SBDPs of $1.58 \mathrm{ng} / \mathrm{ml}$, the sensitivity and specificity for HIE diagnosis was 84.6 and $87.5 \%$, respectively. The ROC analysis for Tau protein yielded a sensitivity and specificity of 79.5 and $96.9 \%$, respectively, at a critical plasma concentration of $4.76 \mathrm{pg} / \mathrm{ml}$. Given our results, SBDPs and Tau proteins are very useful for the early diagnosis of HIE. Early application of mild hypothermia therapy for the treatment of HIE can greatly improve the function of neural development. These findings should greatly improve the evaluation and treatment approaches for HIE.

\section{Introduction}

Neonatal hypoxic-ischemic encephalopathy (HIE), mostly caused by perinatal asphyxia, usually leads to brain damage, manifested mainly by physical development retardation and neurological system dysfunction and even mortality (1). There are various factors influencing the occurrence of HIE, maternal factors are predominant and include pregnancy complications such as advanced age, infections, abnormalities in amniotic fluid, and other important factors such as pre- and post-mature delivery, low birth weight, and birth injury (2). It is difficult to obtain an early diagnosis of HIE, because of the lack of specific clinical manifestations and the imperfection in neonatal neurological development. Moreover, the rates of misdiagnosis and missed diagnosis by clinical observation of activity and application of neonatal behavioral neurological assessment (NBNA) scoring are relatively high, due to inaccurate NBNA scoring, and the low positive diagnostic rates of EEG detection (3). Under hypoxic-ischemic conditions, the brain cells exhibit poor tolerability, which leads to various abnormally expressed proteins. Spectrin breakdown products (SBDPs) of rats that facilitate the secretion of inflammatory factors and transmitters have relatively high tissue specificity and are consistently elevated during brain injury with higher levels corresponding to more severe injury (4). The microtubule-associated Tau protein levels in plasma are closely related to neuronal loss and cognitive impairment (5). Among various options for HIE treatment, mild hypothermia is one of the most promising therapies (6), its therapeutic mechanism, however, remains to be elucidated. The NBNA scoring and the Gesell development scale are frequently utilized tools in efficacy evaluation of the treatment for HIE. 
Table I. Comparison of neonatal baseline materials in each group.

\begin{tabular}{lcccc}
\hline Groups & Male/female & $\begin{array}{c}\text { Average age } \\
\text { in hours (h) }\end{array}$ & $\begin{array}{c}\text { Average of gestational } \\
\text { age (weight) }\end{array}$ & Birth weight (kg) \\
\hline Control group (n=30) & $18 / 12$ & $7.5 \pm 1.6$ & $38.4 \pm 0.6$ & $3.6 \pm 0.5$ \\
Group with mild symptoms (n=30) & $17 / 13$ & $7.9 \pm 2.3$ & $38.5 \pm 0.5$ & $3.7 \pm 0.7$ \\
Group with moderate symptoms (n=60) & $34 / 26$ & $7.6 \pm 1.5$ & $38.3 \pm 0.7$ & $3.8 \pm 0.6$ \\
Group with severe symptoms (n=60) & $35 / 25$ & $8.3 \pm 2.1$ & $38.2 \pm 0.8$ & $3.5 \pm 0.5$ \\
\hline
\end{tabular}

Table II. Inter-group comparisons of the levels of SBDPs at different time-points among groups ( $\mathrm{ng} / \mathrm{ml})$.

\begin{tabular}{lccccc}
\hline Groups & $\begin{array}{c}\text { Before } \\
\text { treatment }\end{array}$ & $\begin{array}{c}\text { 1st day after } \\
\text { treatment }\end{array}$ & $\begin{array}{c}\text { 3rd day after } \\
\text { treatment }\end{array}$ & $\begin{array}{c}\text { 5th day after } \\
\text { treatment }\end{array}$ & $\begin{array}{c}\text { 7th day after } \\
\text { treatment }\end{array}$ \\
\hline $\begin{array}{l}\text { Control group } \\
\text { Group with mild symptoms }\end{array}$ & $1.32 \pm 0.23$ & $1.43 \pm 0.33$ & $1.23 \pm 0.24$ & $1.05 \pm 0.43$ & $1.12 \pm 0.35$ \\
$\begin{array}{l}\text { Group with moderate symptoms } \\
\text { treated by regular therapy }\end{array}$ & $3.26 \pm 0.45$ & $3.02 \pm 0.52$ & $2.86 \pm 0.63$ & $2.75 \pm 0.42$ & $2.66 \pm 0.37$ \\
$\begin{array}{l}\text { Group with moderate symptoms } \\
\text { treated by mild hypothermia therapy }\end{array}$ & $4.68 \pm 0.68$ & $4.56 \pm 0.67$ & $4.42 \pm 0.59$ & $4.27 \pm 0.54$ & $4.03 \pm 0.53$ \\
$\begin{array}{l}\text { Group with severe symptoms treated } \\
\text { by regular therapy }\end{array}$ & $6.85 \pm 1.23$ & $6.23 \pm 1.15$ & $6.10 \pm 1.05$ & $5.89 \pm 0.98$ & $5.76 \pm 0.93$ \\
$\begin{array}{l}\text { Group with severe symptoms treated } \\
\text { by mild hypothermia therapy }\end{array}$ & $6.86 \pm 1.32$ & $5.62 \pm 1.25$ & $5.30 \pm 1.13$ & $5.12 \pm 1.10$ & $4.76 \pm 0.86$ \\
\hline
\end{tabular}

SBDPs, spectrin breakdown products.

Taking all this information into account, we hypothesized that plasma and urine levels of SBDPs and Tau proteins could be used for diagnosis of HIE. Furthermore, a mild hypothermia therapy for HIE in newborns would be beneficial and would lower the above factor levels. We set up groups of infant patients and experiments to test these ideas observing the ethical clinical conditions of our hospital.

\section{Patients and methods}

General considerations. In total 150 patients with neonatal HIE diagnosed within the first $12 \mathrm{~h}$ after birth, in accordance with the revised diagnostic criteria and clinical grading criteria of the Neonatal Group of Chinese Pediatric Society of Chinese Medical Association, were continuously selected from June 2014 to December 2015. There were 30 cases with mild symptoms, 60 cases with moderate symptoms and 60 cases with severe symptoms. During the same period, 30 infants admitted to this hospital for neonatal pneumonia were enrolled for the control group. There were four main criteria for exclusion from the study, listed as follows:

i) All newborns whose gestational age was $<36$ weeks or $>40$ weeks.

ii) Infants with congenital malformations, intracranial hemorrhage, severe anemia (HB $<120 \mathrm{~g} / \mathrm{l})$, intracranial infection, congenital heart disease, hereditary metabolic disease or intrauterine infection.

iii) Infants with maternal diseases such as gestational hypertension, diabetes and abnormal placental function. iv) Infants with severe septicemia, coagulation disorders or blood platelet counts $<50 \times 10^{9} / 1$.

The Ethics Committee of the Xuzhou Children's Hospital approved this study, and all of the guardians of the newborns signed informed consent. Baseline characteristics of newborns in each conformed group were similar (Table I).

Methods. Newborns treated with regular therapy included those in the control and mild symptoms groups and 30 patients from the moderate symptoms and 30 from the severe symptoms groups. Standard guidelines were followed to maintain normal blood pressure and acid-base balance, to decrease the intracranial pressure, providing nutrition support and keeping the rectal temperature between 36 and $37^{\circ} \mathrm{C}$, and for prophylaxis and management of convulsions. On the 1st, 3rd, 5th and 7th days after birth, blood and urine samples were collected from each patient and preserved. The sera were centrifuged for $5 \mathrm{~min}$ at $2,800 \mathrm{xg}$ and the supernatants were saved at $-20^{\circ} \mathrm{C}$ for later assays. The expression levels of SBDPs and Tau protein were measured by sandwich enzyme-linked immunosorbent (ELISA) assay. ELISA kits were provided by Sigma-Aldrich (St. Louis, MO, USA) and microplate readers were provided by Bio-Rad Laboratories, Inc. (Hercules, CA, USA). All the procedures were followed, adhering strictly to the manufacturer's instructions.

The other 60 patients, 30 from each the moderate symptoms and severe symptoms groups, were treated with mild hypothermia therapy, and the group with severe symptoms treated with regular therapy. In these cases, selective head 
Table III. Inter-group comparisons of levels of Tau at different time-points (pg/ml).

\begin{tabular}{|c|c|c|c|c|c|}
\hline Groups & $\begin{array}{c}\text { Before } \\
\text { treatment }\end{array}$ & $\begin{array}{l}\text { 1st day after } \\
\text { treatment }\end{array}$ & $\begin{array}{l}\text { 3rd day after } \\
\text { treatment }\end{array}$ & $\begin{array}{l}5 \text { th day after } \\
\text { treatment }\end{array}$ & $\begin{array}{c}\text { 7th day after } \\
\text { treatment }\end{array}$ \\
\hline Control group & $3.42 \pm 1.37$ & $4.42 \pm 1.43$ & $3.68 \pm 1.73$ & $4.47 \pm 1.85$ & $4.12 \pm 1.35$ \\
\hline Group with mild symptoms & $7.35 \pm 1.24$ & $7.12 \pm 1.33$ & $6.89 \pm 1.27$ & $6.72 \pm 1.05$ & $6.43 \pm 0.89$ \\
\hline $\begin{array}{l}\text { Group with moderate symptoms treated } \\
\text { by regular therapy }\end{array}$ & $9.24 \pm 1.43$ & $8.97 \pm 1.46$ & $8.46 \pm 1.53$ & $8.20 \pm 1.13$ & $7.85 \pm 1.22$ \\
\hline $\begin{array}{l}\text { Group with moderate symptoms treated } \\
\text { by mild hypothermia therapy }\end{array}$ & $9.36 \pm 1.27$ & $8.55 \pm 1.32$ & $8.21 \pm 1.56$ & $7.56 \pm 1.42$ & $7.24 \pm 0.95$ \\
\hline $\begin{array}{l}\text { Group with severe symptoms treated } \\
\text { by regular therapy }\end{array}$ & $13.52 \pm 2.52$ & $13.20 \pm 2.34$ & $12.86 \pm 2.52$ & $12.66 \pm 2.37$ & $11.85 \pm 2.74$ \\
\hline $\begin{array}{l}\text { Group with severe symptoms treated } \\
\text { by mild hypothermia therapy }\end{array}$ & $14.26 \pm 2.85$ & $12.87 \pm 2.54$ & $11.85 \pm 2.49$ & $10.75 \pm 2.49$ & $10.49 \pm 2.48$ \\
\hline
\end{tabular}

cooling therapy (Olympic Cool-Cap system) was performed 6-12 $\mathrm{h}$ after birth, and an intravenous infusion of saline at $4^{\circ} \mathrm{C}$ was set in place, combined with a computer-controlled hypothermic blanket for low-temperature inducement with a cooling rate of $0.5-1^{\circ} \mathrm{C} / \mathrm{h}$. Finally, the rectal temperature was kept between 32 and $34^{\circ} \mathrm{C}$ for $24 \mathrm{~h}$. Then, natural re-warming was applied during the course of $8 \mathrm{~h}$, and the temperature of newborns returned to levels between 37 and $37.5^{\circ} \mathrm{C}$. On the 1st, 3rd, 5th and 7th days after birth, blood and urine samples were collected and saved for the detection of expression levels of SBDPs and Tau protein.

Detection method. For the sandwich ELISA tests, the samples were first defrozen to room temperature. Then aliquots $(100 \mu \mathrm{l})$ of coated antibody were pipetted into the wells on a microplate, which was covered by adhesive foil and kept for $24 \mathrm{~h}$ under constant temperature $\left(4^{\circ} \mathrm{C}\right)$ to coat the microplate. The plate was washed 3 times with a microplate washer. Standards were prepared by diluting $10 \mu \mathrm{l}$ with $40 \mu \mathrm{l}$ of dilution solution and added into each well, and then each plate was covered with adhesive foil and incubated for $60 \mathrm{~min}$ at $43^{\circ} \mathrm{C}$. For washing the plates the adhesive foils were opened and the plates were washed 3 times with a microplate washer, letting the plate stand for a full minute between washes. Then the samples were mixed with a conjugate solution and $50 \mu 1$ were added to each well for incubation for $60 \mathrm{~min}$ at $43^{\circ} \mathrm{C}$. After the incubation time, the plates were washed 3 times with the microplate washer letting the plates stand between washes for $40 \mathrm{sec}$. Finally, for coloration and to stop the reaction, $50 \mu \mathrm{l}$ substrate solution A and $50 \mu \mathrm{l}$ of solution B were pipetted into each standard well, mixed, and placed in the dark for $15 \mathrm{~min}$ at $20^{\circ} \mathrm{C}$. After that, $50 \mu \mathrm{l}$ of stopping solution were added. A microplate reader was used for obtaining OD values after $15 \mathrm{~min}$; the concentrations of correspondent samples were calculated from a standards plot.

Indicators for follow-up. The clinical conditions after 28 days, 3, 6 and 12 months were evaluated. Comprehensive physical (weight, body length and head circumference) and neurological development examinations were performed. On the 28th day after birth, the NBNA scoring was determined, including an assessment of behavioral ability (6 items), passive muscular tone (4 items), active muscular tone ( 4 items), primitive reflexes (3 items) and general evaluation ( 3 items). The total points for a perfect score were set at 40 (each item was given $0-2$ points). The assessment was performed during the course of an hour after breast-feeding under quiet, semi-dark and room temperature conditions. Any score $<35$ points indicated brain injury, a score between 35 and 37 points indicated suspected brain injury and a score of $\geq 37$ points indicated normal development. The developmental quotient (DQ) tests were performed at 3, 6 and 12 months after birth using the Gesell development scale. The test included adaptability, gross motor and fine movement, language, and social contact. The results of each test were presented as DQ, in which $55-75$ points indicated mild intelligence disability, 40-54 points indicated moderate intelligence disability and points $<40$ indicated severe intelligence disability.

Statistical analysis. SPSS 19.0 software (Chicago, IL, USA) was applied for statistical data analysis. Quantitative data were presented as mean \pm standard deviation, $t$-test or analysis of variance (ANOVA) were performed in the comparison among groups, LSD t-test was used for comparisons between any two groups, and ANOVA of repeated measurement data were carried out in comparisons of different time-points within one group. Data are presented as percentages, and $\chi^{2}$ test was applied in comparison among groups. SBDPs and Tau, used as diagnostic criteria, were analyzed by a receiver operating characteristic (ROC) curve. Differences with $\mathrm{P}<0.05$ were considered as statistically significant.

\section{Results}

Inter-group comparison of the levels of SBDPs and of Tau protein at different time-points. At each time-point, the plasma levels of SBDPs and Tau protein increased with the enhancement of HIE severity and decreased with the prolongation in treatment duration in each group with statistically significant differences between the averages in all groups $(\mathrm{P}<0.05)$. For groups with moderate and severe symptoms treated with mild hypothermia therapy, the levels of SBDPs and Tau protein at any point in time were significantly lower than those of groups treated with regular therapy $(\mathrm{P}<0.05)$ (Tables II and III). 
Table IV. Inter-group comparisons of NBNA scores in follow-up period.

\begin{tabular}{lcccccc}
\hline Groups & $\begin{array}{c}\text { Control } \\
\text { group }\end{array}$ & $\begin{array}{c}\text { Group } \\
\text { with mild } \\
\text { symptoms }\end{array}$ & $\begin{array}{c}\text { Group with moderate } \\
\text { symptoms treated by } \\
\text { regular therapy }\end{array}$ & $\begin{array}{c}\text { Group with moderate } \\
\text { symptoms treated by mild } \\
\text { hypothermia therapy }\end{array}$ & $\begin{array}{c}\text { Group with severe } \\
\text { symptoms treated by } \\
\text { regular therapy }\end{array}$ & $\begin{array}{c}\text { Group with severe } \\
\text { symptoms treated by mild } \\
\text { hypothermia therapy }\end{array}$ \\
\hline 28 days & $39.5 \pm 2.4$ & $37.2 \pm 2.3$ & $35.4 \pm 2.1$ & $36.8 \pm 2.2$ & $34.7 \pm 3.0$ & $35.8 \pm 3.2$ \\
\hline
\end{tabular}

NBNA, neonatal behavioral neurological assessment.

Table V. Inter-group comparison of DQ in follow-up period.

\begin{tabular}{|c|c|c|c|}
\hline Groups & 3rd month & 6th month & 12th month \\
\hline Control group & $82.4 \pm 3.6$ & $83.5 \pm 4.7$ & $84.2 \pm 5.3$ \\
\hline Group with mild symptoms & $77.2 \pm 4.3$ & $78.3 \pm 4.6$ & $79.4 \pm 5.2$ \\
\hline Group with moderate symptoms treated with regular therapy & $72.4 \pm 6.3$ & $73.6 \pm 6.6$ & $75.4 \pm 6.8$ \\
\hline Group with moderate symptoms treated with mild hypothermia therapy & $72.3 \pm 6.5$ & $74.8 \pm 6.3$ & $75.8 \pm 6.2$ \\
\hline Group with severe symptoms treated with regular therapy & $67.5 \pm 8.3$ & $68.3 \pm 8.5$ & $71.2 \pm 8.7$ \\
\hline Group with severe symptoms treated with mild hypothermia therapy & $67.2 \pm 7.3$ & $71.3 \pm 7.4$ & $73.5 \pm 7.7$ \\
\hline
\end{tabular}

DQ, developmental quotient.

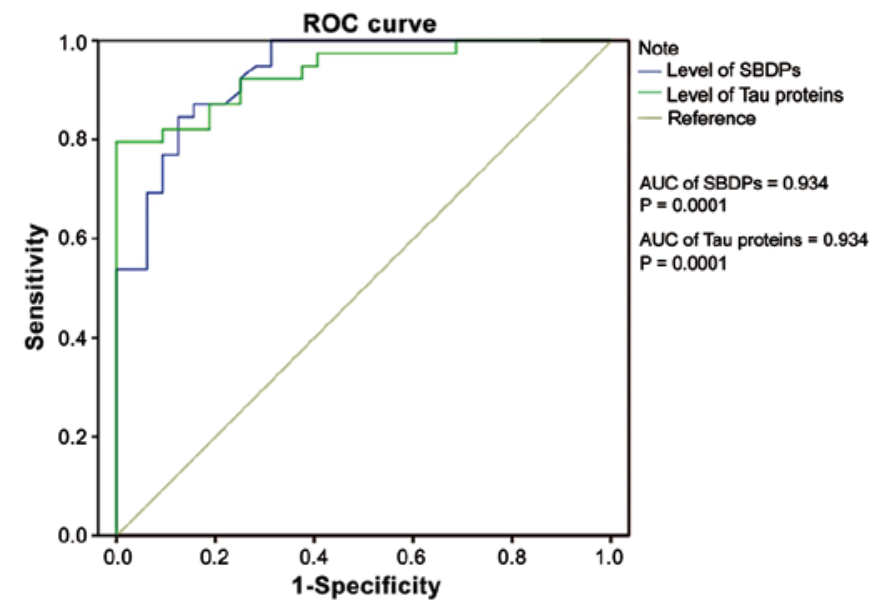

Figure 1. Analysis of ROC curve for diagnosis in accordance with the levels of SBDPs and Tau protein. ROC, receiver operating characteristic; SBDPs, spectrin breakdown products.

Inter-group comparison of NBNA scores during the follow-up period. During the follow-up period, the NBNA score decreased with the increase of HIE severity. For groups with moderate and severe symptoms treated by mild hypothermia therapy, the NBNA score was significantly better than that of groups treated with regular therapy $(\mathrm{P}<0.05)$ (Table IV).

Inter-group comparison of $D Q$ during the follow-up period. At each time-point, DQ was worse with the augmentation of HIE severity and improved with the prolongation in treatment duration in each group, with statistically significant differences between the averages of different groups $(\mathrm{P}<0.05)$. For groups with moderate and severe symptoms treated by mild hypothermia therapy, DQ at any point in time was significantly better than that of groups treated with regular therapy $(\mathrm{P}<0.05)$ (Table $\mathrm{V})$.

Analysis of ROC curve for diagnosis of HIE according to the levels of SBDPs and Tau protein. The area under the curve (AUC) of ROC for HIE diagnosis in accordance with the level of SBDPs was $0.934(\mathrm{P}=0.0001)$. The sensitivity and specificity of diagnosis reached 84.6 and $87.5 \%$, respectively, when the critical point was $1.58 \mathrm{ng} / \mathrm{ml}$ (Fig. 1).

The AUC of ROC for HIE diagnosis according with the level of Tau was $0.934(\mathrm{P}=0.0001)$. The sensitivity and specificity of diagnosis reached 79.5 and $96.9 \%$, respectively, when the critical point was $4.76 \mathrm{pg} / \mathrm{ml}$ (Fig. 1).

\section{Discussion}

The pathogenesis of HIE is complicated, it can include calcium overload, a cytokine storm, reperfusion injury, cellular apoptosis and dysfunction of energetic metabolism and others (7). Under normal conditions, the rates of formation and clearance of oxygen-free radicals remain in dynamic equilibrium (8). However, this equilibrium becomes disrupted when the brain tissues are under hypoxic ischemic states, forming enormous quantities of oxygen-free radicals and enhancing the response to oxidative stress. Newborns are usually highly susceptible to oxidative injury due to a high content of polyunsaturated fatty acids in their brain. However, in most cases of moderate and severe HIE, patients suffer from neurological sequelae (9).

Regular symptomatic treatment of HIE includes maintaining adequate heart and ventilation rates, lowering intracranial pressure, keeping $\mathrm{pH}$ and electrolyte balances and prophylaxis against convulsions. In addition, some drugs such as allopurinol, anti-apoptosis drugs and deferoxamine are sometimes used to promote the synthesis of EPO and 
inhibit the process of cellular apoptosis (10). Through mild hypothermia therapy, the head of a newborn is kept in a low-temperature environment $\left(27^{\circ} \mathrm{C}\right)$, resulting in a decrease in the release of excitatory neurotransmitters, with a decrease in the rate of formation of oxygen-free radicals and inhibition of apoptosis of neurons (11). The underlying mechanisms are not fully understood but include a decrease in the concentration of SBDPs (12). By suppressing neuronal apoptosis, the large release of caspase-3 is blocked, leading to decreases in SBDPs. Downregulation of the activity of glial cells helps to avoid the excessive activation of inflammatory factors, protecting the nerve and preventing the exacerbation of brain injury (13). The low-temperature stabilizes the plasmalemma of brain cells, alleviating the effect of peroxidation reactions, regulating the phosphorylation of Tau proteins, reducing the possibility of breakdown of microtubules, maintaining the regular morphology of neurons and axonal transport and mitigating brain injuries (14).

Usually, SBDPs exists in the neuron axon and presynaptic terminals. At the beginning of HIE, large amounts of calpain-2 and caspase- 3 are activated and accelerate apoptosis and necrosis of brain cells, leading to brain injuries. However, to hydrolyze calpain-2 and caspase- 3 , mass SBDPs are produced, which can affect the distribution of SBDPs in neuronal axons, resulting in axotomy. This process is irreversible. Thus, SBDPs do not only indicate brain injuries, but also contribute to the pathological mechanism of apoptosis and necrosis of brain cells $(12,15)$. Under normal circumstances, Tau proteins have two forms, dephosphorylated form and phosphorylated, in a balanced state. During the progress of HIE, the Tau protein gets excessively phosphorylated, which affects its normal physiological functions. The Tau protein accumulates in neurons, altering the normal formation of microtubules. Besides, it also splits the normal microtubule-related proteins from the microtubule, leading to the collapse of microtubule, and creating large amounts of deposited matter inside the neurons damaging them $(16,17)$.

In this study, at any time, the mild hypothermia therapy improved the levels of SBDPs and Tau proteins and also the NBNA scores and DQ values. The levels of SBDPs and Tau proteins showed good sensitivity, specificity and accuracy in diagnosis of HIE. Thus, early diagnosis of HIE using SBDPs and Tau protein levels should lead to prompt treatment with mild hypothermia for improving neurological function development and prognosis of HIE infants.

\section{References}

1. Boix H: Are we doing our best for our patients with hypoxic-ischaemic encephalopathy? An Pediatr (Barc): May 24, 2016 (In Spanish) (Epub ahead of print).
2. Xu J, Gang QQ, Hao P and Zhang JN: Pathological and magnetic resonance imaging findings in a neonatal Tibet minipig model of hypoxic-ischemic encephalopathy. Nan Fang Yi Ke Da Xue Xue Bao 36: 705-709, 2016 (In Chinese).

3. Rumajogee P, Bregman T, Miller SP, Yager JY and Fehlings MG: Rodent hypoxia-ischemia models for cerebral palsy research: a systematic review. Front Neurol 7: 57, 2016.

4. Chen S, Shi Q, Zheng S, Luo L, Yuan S, Wang X, Cheng Z and Zhang W: Role of $\alpha$-II-spectrin breakdown products in the prediction of the severity and clinical outcome of acute traumatic brain injury. Exp Ther Med 11: 2049-2053, 2016.

5. Lv H, Wang Q, Wu S, Yang L, Ren P, Yang Y, Gao J and Li L: Neonatal hypoxic ischemic encephalopathy-related biomarkers in serum and cerebrospinal fluid. Clin Chim Acta 450: 282-297, 2015.

6. Elbahtiti A, Aly NY, Abo-Lila R and Al-Sawan R: Therapeutic hypothermia for infants with hypoxic ischemic encephalopathy: a five years' single center experience in Kuwait. J Neonatal Perinatal Med 9: 179-185, 2016.

7. Demarest TG, Schuh RA, Waddell J, McKenna MC and Fiskum G: Sex-dependent mitochondrial respiratory impairment and oxidative stress in a rat model of neonatal hypoxic-ischemic encephalopathy. J Neurochem 137: 714-729, 2016.

8. Kumar A, Mittal R, Khanna HD and Basu S: Free radical injury and blood-brain barrier permeability in hypoxic-ischemic encephalopathy. Pediatrics 122: e722-e727, 2008.

9. Fisher PG: Are neonatal stroke and hypoxic-ischemic encephalopathy related? J Pediatr 173: 1-3, 2016.

10. Wu YW, Mathur AM, Chang T, McKinstry RC, Mulkey SB, Mayock DE, Van Meurs KP, Rogers EE, Gonzalez FF, Comstock BA, et al: High-dose erythropoietin and hypothermia for hypoxic-ischemic encephalopathy: a phase II trial. Pediatrics 137: 123-124, 2016.

11. Sabir H, Osredkar D, Maes E, Wood T and Thoresen M: Xenon combined with therapeutic hypothermia is not neuroprotective after severe hypoxia-ischemia in neonatal rats. PLoS One 11: e0156759, 2016.

12. Kobeissy FH, Liu MC, Yang Z, Zhang Z, Zheng W, Glushakova O, Mondello S, Anagli J, Hayes RL and Wang KK: Degradation of $\beta$ II-spectrin protein by calpain- 2 and caspase- 3 under neurotoxic and traumatic brain injury conditions. Mol Neurobiol 52: 696-709, 2015.

13. Gabriel ML, Braga FB, Cardoso MR, Lopes AC, Piatto VB and Souza AS: The association between pro- and anti-inflammatory cytokine polymorphisms and periventricular leukomalacia in newborns with hypoxic-ischemic encephalopathy. J Inflamm Res 9: 59-67, 2016.

14. Liu F, Yang S, Du Z and Guo Z: Dynamic changes of cerebral-specific proteins in full-term newborns with hypoxic-ischemic encephalopathy. Cell Biochem Biophys 66: 389-396, 2013.

15. Witek MA and Fung LW: Quantitative studies of caspase-3 catalyzed $\alpha$ II-spectrin breakdown. Brain Res 1533: 1-15, 2013.

16. Ojo JO, Mouzon B, Algamal M, Leary P, Lynch C, Abdullah L, Evans J, Mullan M, Bachmeier C, Stewart W, et al: Chronic repetitive mild traumatic brain injury results in reduced cerebral blood flow, axonal injury, gliosis, and increased T-Tau and Tau oligomers. J Neuropathol Exp Neurol 75: 636-655, 2016.

17. Zhao J, Chen Y, Xu Y and Pi G: Effects of PTEN inhibition on the regulation of Tau phosphorylation in rat cortical neuronal injury after oxygen and glucose deprivation. Brain Inj 30: $1150-1159,2016$. 